\title{
Multilingual advertising in the linguistic landscape of Seoul
}

\section{Jamie Shinhee Lee}

University of Michigan-Dearborn

\section{Correspondence}

Jamie Shinhee Lee, University of MichiganDearborn, 3069 CASL Building, 4901 Evergreen Rd, Dearborn, MI 48128.

Email:jamilee@umich.edu

\begin{abstract}
This study examines commercial signs in arguably the two most visited tourism districts in Seoul, namely Myeongdong and Insadong. It focuses on beauty and food businesses and analyzes featured languages and their content and roles in signage. This article argues that business types, specialized marketing focus, and intended sales pitch influence business owners' linguistic choices. The findings of the study suggest that the beauty industry relies heavily on English in general, but the power of K-Beauty popularized by 'Hallyu' (The Korean Wave) beyond Korea inevitably invites linguistic accommodation in the form of using Chinese and Japanese. In general, the business category of beauty features a more prevalent use of English than the gastronomic business in this study. Moreover, as an area specializing in traditions and cultural heritage, Insadong shows more signs exclusively in Korean than in Myeongdong.
\end{abstract}

\section{1 | INTRODUCTION}

We have recently observed increasing research interest in linguistic landscapes (Lawrence, 2012). The importance of the linguistic landscape in sociolinguistic research is noted by Scollon and Scollon (2003) who assert that 'we speak and listen, write and read not only about the world but in the world, and much of what we understand depends on exactly where we and the language are located in the world' ( $p$. ix, emphasis in the original). This paper considers the linguistic landscape as advertising texts and analyzes approximately 300 shop signs collected from arguably the two most visited tourism districts in Seoul, South Korea. As Vestergaard and Schrøder (1994) argue, 'the ultimate aim of all advertising is to sell the commodity' (p. 49), and shop signs essentially have the same goal. Similar to commercials, shop signs also aim to capture people's attention with the goal of encouraging the purchase of goods and services. Lund's (1947) task of the adman includes attracting attention, arousing attention, stimulating desire, creating conviction, and getting action (cited in Vestergaard \& Schrøder, 1994, p. 49), which I argue can be fulfilled by the linguistic landscape as well.

Investigating which languages are utilized and how they are used in the linguistic landscape, we can reasonably deduce some important sociolinguistic phenomena, including and not limited to language ideologies, functional and pragmatic divisions of labor among languages at play and the power dynamics among them. In fact, both 
Spolsky and Cooper (1991) and Cenoz and Gorter (2006) attempt to answer questions that touch on the aspects of the linguistic landscape mentioned above, including languages used and the order in which they appear (Spolsky \& Cooper, 1991, p. 76) and the location/placement, font size, and the amount and kind of information represented by each of the languages used (Cenoz \& Gorter, 2006, pp. 68-70). Most studies on the linguistic landscape, however, tend to survey several areas in general, not focusing specifically on products or business types with the exception of a few (Ong, Wee, François, \& Serwe, 2013). Product and service types can influence language choices (Selvi, 2016). Although she is not concerned with the linguistic landscape per se, in her research on Korean TV commercials, Lee (2006) reports that English is used mostly in technology-related products and beauty products, whereas food is generally advertised exclusively in Korean. More than 12 years later in another sociolinguistic domain called the linguistic landscape, it would be interesting to see if similar patterns exist or if we see something entirely different. This study focuses on two main types of businesses commonly found in Myeongdong and Insadong in Seoul: beauty and food. It would be worth comparing the linguistic landscape of Insadong-known for traditional tea, food, and artifacts - with that of Myeongdong, downtown Seoul-packed with modern clothing stores and restaurants.

\section{2 | ENGLISH IN THE KOREAN LINGUISTIC LANDSCAPE}

Bolton (2012) notes that the growing use of English in linguistic landscapes can be explained in connection with the notion of 'economic and cultural globalization' (p. 32). Many previous studies on English in commercial text tend to characterize English 'as an attention getter and as a symbolic marker indexing consumer's modern, global and internationalized orientation' (Lee, 2010, p. 112). Weyers (2015) also notes that English is used in the retail landscape of a Columbian city because it is often associated with 'prosperity' and 'status' (p. 8). He further argues that, 'as an appeal to their potential clientele's desire for higher social status', business owners opt for English names (p. 13). Similarly, Lanza and Woldemariam (2014) argue that 'power and prestige intersect with English' in the linguistic landscape in Ethiopia (p. 498). Ross (1997) notes that English 'lends an aura of chic prestige to a business' (p. 31). Similarly, Vandenbroucke (2016) also shows that 'English visibility' is associated with 'upscale and 'downscale spaces' (p. 93). Using Bourdieu's (1991) notion of the 'linguistic marketplace', Vandenbroucke (2016) looks at 'hierarchically ordered' languages and their attributed symbolic values as 'commodities' (p. 87), arguing that 'symbolic power for shop owners is arguably indirectly linked to the commercial success of the enterprise and to an increase in the client reach' (ibid.). According to Vandenbroucke (2016), English serves 'as a vehicle of association, invoking profitable qualities and values vis-a-vis the brand and the commodities on sale in a particular market' (p. 97).

As for the purposes English serves in linguistic landscapes of the Outer Circle and the Expanding Circle countries, two different positions have been proposed: superficial and symbolic or substantial and pragmatic, as similarly reported in research on English mixing in non-English language advertising (Bhatia, 1992; Bhatia, 2008; Martin, 2007). Tan and Tan (2015) argue that 'English is actually functioning as a status marker' and view the use of English as 'symbolic rather than information-giving in nature' (pp. 75-76). Similarly, Kasanga's (2012) research notes that English is used mainly for 'aesthetic, symbolic, and promotional purposes' because of its 'positive ethnolinguistic values, global symbolic power, and ornamental effects' (p. 66). On the other hand, Inagawa (2015) suggests that English expressions on Japanese posters and in advertising texts are not simply 'decorative or attention-grabbing devices'; they do 'have functional purposes or persuasive effects in the form of wordplay, engaging the audience in thought-provoking ways and conveying messages in an effective and pun-like manner' (p. 16). As for other reasons why English is used, Pakistani business owners, in a study by Manan, David, Dumanig, and Channa (2017), characterize English as a (1) modern language; (2) fashionable language; and (3) local language which provides 'linguistic richness' and 'attractiveness' and sometimes compensates for 'inexpressiveness of Urdu and other languages' (p. 656). Manan 
et al. (2017) discuss English as 'a brand signifier', 'a cosmetic vehicle', 'an economic and commercial commodity', and 'a flexible communicative resource' in their study on the Pakistan linguistic landscape (pp. 659-661). According to the advertisers in their research, English 'adds an aura of sophistication and embellishment to their products/services', serving as 'the most attractive language for advertisement' (p. 660).

Business types seem to be an important factor in shop owners' linguistic choices. Selvi (2016) reports that business types influence the use of English in Turkey. For example, his study reveals that 'cosmetic stores, restaurants, cafés and electronics retail stores were more prone to the use of English' and 'stores selling durable consumer goods, pharmacies, car dealerships, gas stations, mechanics, museums, libraries, driving schools, bookstores, publishing houses, law offices, insurance agencies, and NGOs almost had no place for the English language occurrences' (p. 35). Dimova's (2007) research on Macedonian shop signs revealed that 100 per cent of Internet cafés, 88 per cent of bars, 48 per cent of boutiques, 33 per cent of restaurants, and 20 to 25 per cent of barber shops, bakeries, and groceries used English, whereas no English appeared in the shop signs of butchers and pharmacies (p. 21). English also seems to be perceived as a more useful language addressing benefits and features of modern technology-driven products and services. For example, Pakistani business owners in the study by Manan et al. (2017) value 'the flexibility of the English language', which enables them to 'provide meaningful description to every modern technological product/service' (p. 661).

With reference to the use of English in the Korean linguistic landscape, Lawrence (2012) observes that the frequency of English was highest in Busan (60 per cent), followed by Gangnam in Seoul and Bundang (50 per cent), Shinduri (20 per cent), and Suwon (15 per cent) (p. 88). The present study does not look at cities other than Seoul and investigates two areas in Seoul, primarily focusing on predominant business types, namely food and beauty. Lawrence (2012) notes that English is used more in public signs related to modernity and youth, and regions affiliated with luxurious and modern living (p. 89). In summarizing major findings of earlier research on linguistic landscapes, Lawrence (2012) notes that 'English and other languages are distributed across linguistic landscapes unevenly according to geography' and 'according to domains, with previous research revealing that English seems to be most dominant in the domains of tourism, technology, fashion and 'bottom-up' signs' (p. 75). Even when specific official language policies are available, they are not always executed accordingly in the linguistic landscape. Shang and Guo (2017) observe that 'English is prevalent in all types of shop signs' in Singapore, whereas 'the other official languages are rarely presented on shop signs' (p. 183). They attribute 'the disparate vitality of languages' in the linguistic landscape of Singapore to its 'macro language policy, demographic structure, and ethnic and cultural identity' (p. 183). Manan, David, Dumanig, and Khan (2015) also contend that challenges to the official policy can be motivated by 'pragmatism, religion or identity' and observe that 'the ethnolinguistic dimension' leads to the use of local languages in certain ethnically-oriented areas, such as Chinese and Indian communities (p. 31).

\section{3 | DATA}

The present study is based on digitally documented photographs collected in the summer of 2014. A total of 275 business signs were collected from two of the most popular tourism districts, Myeongdong and Insadong, in Seoul, Korea. This study reports only on the first phase of data collection of a much larger study of the multilingual landscape of Korea, analyzing primarily the qualitative aspect of this data. Drawing upon Leeman and Modan (2009) and Vandenbroucke (2016), data are examined for (1) language combinations; (2) distributive type of English display, that is, English monolingualism or multilingual discourse including full-equivalent English translations, English used for partial translations or less important information, and English used for most commercial information; (3) type of content communicated in English, that is, symbolic or referential or both; and (4) type of commercial establishment, that is, privately owned or (inter)national chain (Vandenbroucke, 2016, p. 90). 


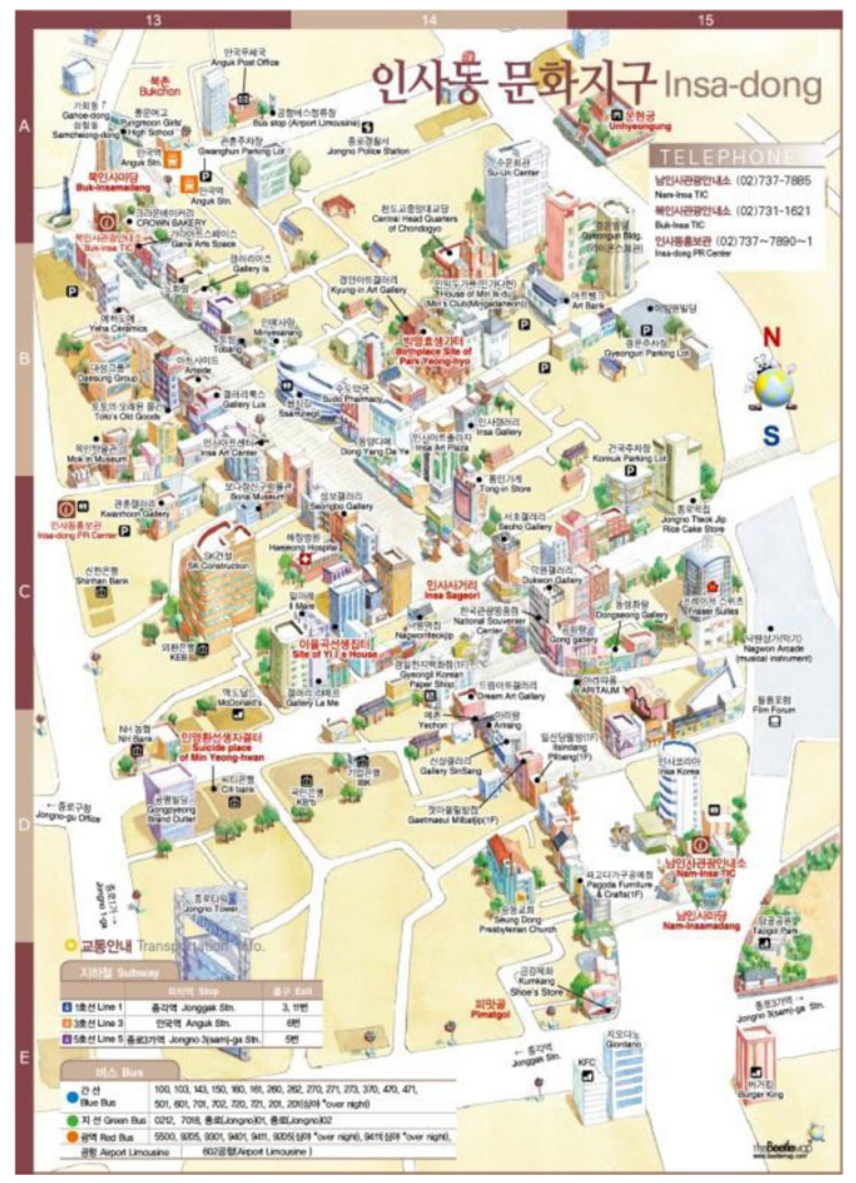

MAP 1 Map of Insadong ${ }^{1}$ [Colour figure can be viewed at wileyonlinelibrary.com]

\section{4 | RESEARCH SITES}

Both locations share something in common: they are well-known tourist areas and arguably equally popular among foreign visitors. However, they are also different; their business focus is dissimilar. Insadong (Map 1) is famous for traditional food, tea, and art galleries. Myeongdong (Map 2) is known for fashion and beauty products. Many clothing stores with high-end designer names are found in Myeongdong, whereas mostly traditional Korean clothing is marketed in Insadong. Linguistically speaking, a distinctive policy favoring the use of Korean exists in Insadong, but such a policy is not in place in Myeongdong. It will be interesting to see if the linguistic landscapes of these two areas show similar patterns.

\section{1 | Insadong}

Insadong showcases 'old but precious and traditional goods' and is 'especially popular among international tourists' because 'they can experience and see traditional Korean culture firsthand, and also purchase pieces of fine art' (Imagine your Korea; Official Korea Tourism Association ${ }^{2}$ ). According to Lee (2018), Insadong has been 'a hub for painting studios, art supply stores, and 'pyogu' (paper or silk framing service for mounted paintings) shops' since the 1960s and has become 'increasingly popular among locals and tourists in the 1990s'. Linguistically speaking, Insadong 


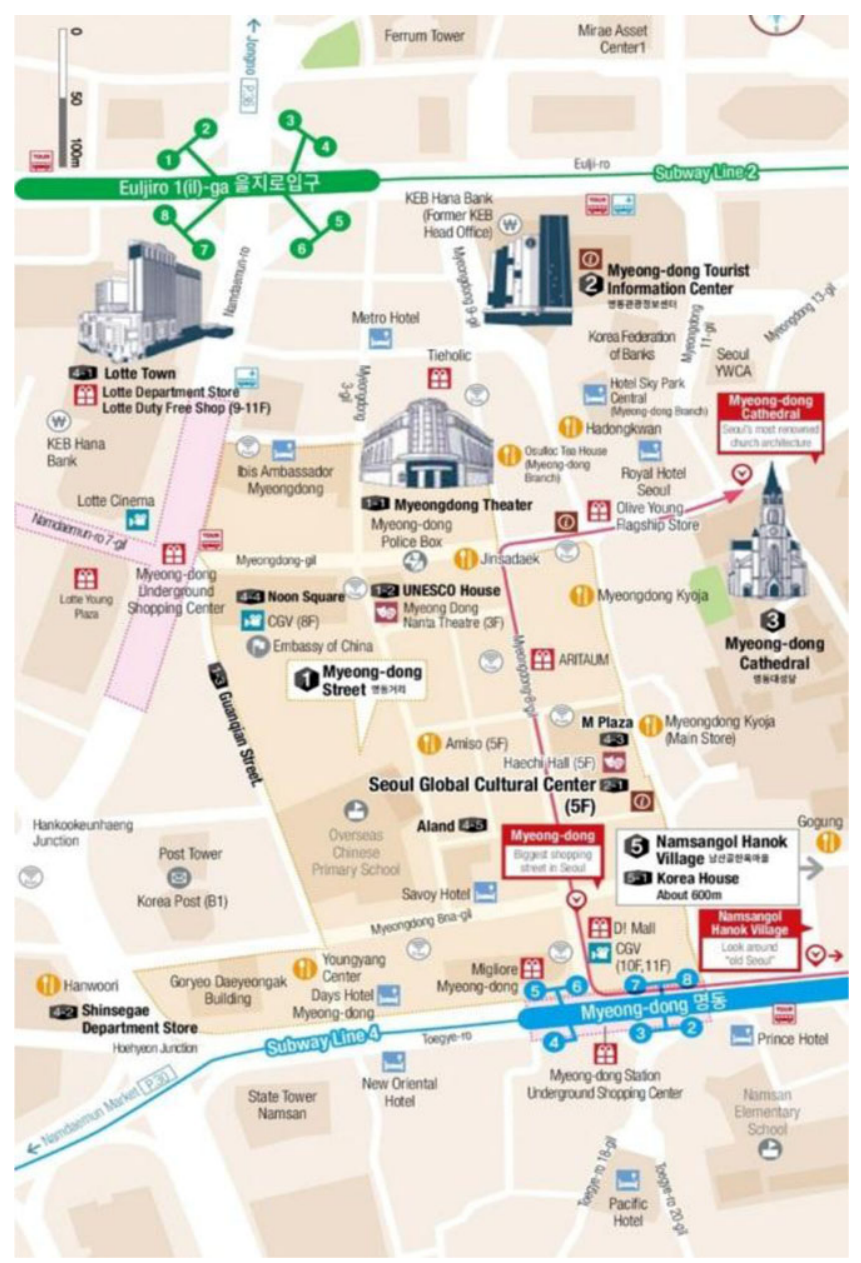

MAP 2 Map of Myeongdong ${ }^{3}$ [Colour figure can be viewed at wileyonlinelibrary.com]

has a unique feature. Lawrence (2012) states that 'due to government regulations, most signs are written in Korean only' (p. 88). Tan and Tan (2015) also agree that 'explicit government effort accounts for the higher numbers of signs with English written in the Hangeul script' in Insadong (p. 73). They further report that 'script mixing is also most visible in the Insadong area. Romanized Korean is likely to take on a decorative or symbolic function as it is seemingly made accessible to foreigners but retaining its Korean meaning, which would not have made much sense to non-Korean speakers' (ibid.).

\section{2 | Myeongdong}

According to the Visit Seoul website, 'Myeongdong is Seoul's shopping mecca and is a must-see for tourists, but it is not just a shopping destination; Myeongdong is also a hub of commerce, banking and culture with a daytime population of 1.5-2 million'. Similar to Insadong, Myeongdong is a popular destination for foreign visitors especially 'Japanese and Chinse tourists during the holiday period known as 'Golden Week' which takes place in spring. ${ }^{4}$ Korea Tourism Organization notes that 'many brand name shops and department stores line the streets and alleys' of Myeongdong, which are not generally found in Insadong. ${ }^{5}$ 


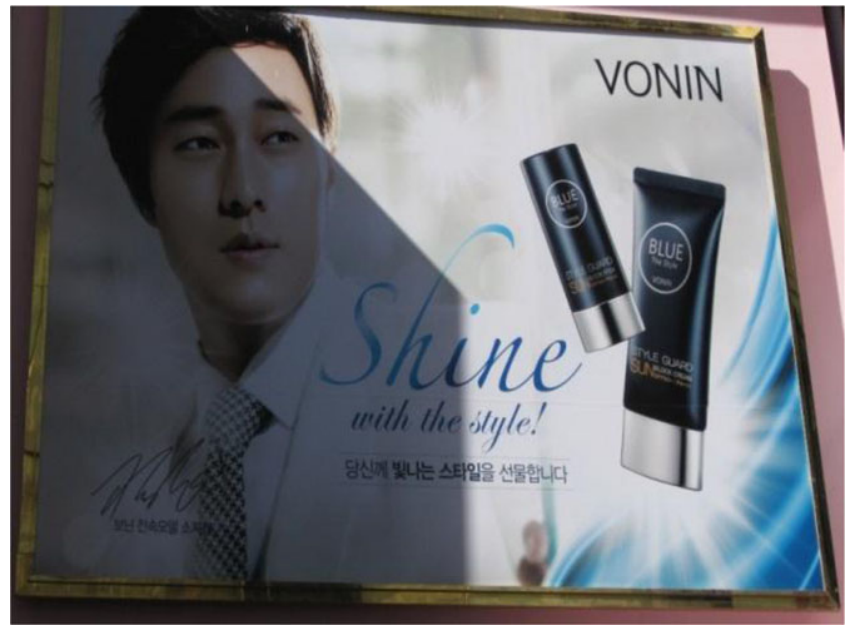

FIGURE 1 Sign advertising a sunblock lotion [Colour figure can be viewed at wileyonlinelibrary.com]

\section{5 | DISCUSSION}

When it comes to marketability in the linguistic landscape, English is often mentioned as 'an economic and commercial commodity' (Manan et al., 2017, p. 660). However, this study argues that other languages, particularly Japanese and Chinese, also serve as marketable languages in signage in South Korea. The analysis of business signs regarding food and beauty products in the two tourism districts in this study reveals some sociolinguistically noteworthy tendencies. English has a strong presence in the linguistic landscape of beauty products. In contrast, restaurants, particularly Korean restaurants, tend to have signs in Korean, but the presence of the Japanese language is also quite prominent. Research conducted by Ong et al. (2013) on Singaporean beauty and food businesses argues that '[their] findings are consonant with the French linguistic fetish documented in other countries as being tied predictably to the food and beauty industries' (p. 24). However, no French was found in the data of the present study. Instead, commercial signs associated with food and beauty items feature multiple languages, including Korean, English, Japanese, and Chinese. When both Chinese and Japanese appear together, Japanese precedes Chinese in most cases.

\section{1 | Beauty}

Myeongdong had significantly more businesses selling beauty products than Insadong. No signs related to cosmetics and beauty products were exclusively in Korean. Chan and Huang (2001) note that branding modern products, such as cosmetics, often rely on foreign names. In advertising beauty products in the Korean linguistic landscape, generally two to four languages are used, mostly Korean and English in product names and catch phrases, and occasionally Japanese and Chinese in descriptions of effects. Another noteworthy feature of advertising texts about cosmetics is the appearance of Korean male singers and actors. The Korean Wave (often known as 'Hallyu'), which refers to 'the flood of Korean pop culture-film, pop music and especially TV dramas-into the rest of East Asia' (Chua \& Iwabuchi, 2008, p. 2), has impacted tourism and consumer markets. Businesses marketing beauty products tend to have signs and posters featuring popular male Hallyu celebrities. Figure 1 is a sign posted on the wall of a cosmetics store in Myeongdong. It advertises a sunblock lotion named BLUE by VONIN and features a well-known actor. The main copy states, 'VONIN Shine with the style! 당신께 빛 나는 스타일 을 선 물합니 다'. Two languages are present in this sign, English appearing first in a larger font and Korean following in smaller print. The Korean portion is not the exact match to the English part, but a near equivalent. The Korean part translates into 'We gift you a shining style'. As Bano and Sharif (2016) argue, 'metrosexual is a lucrative segment as the market of male grooming products is showing 


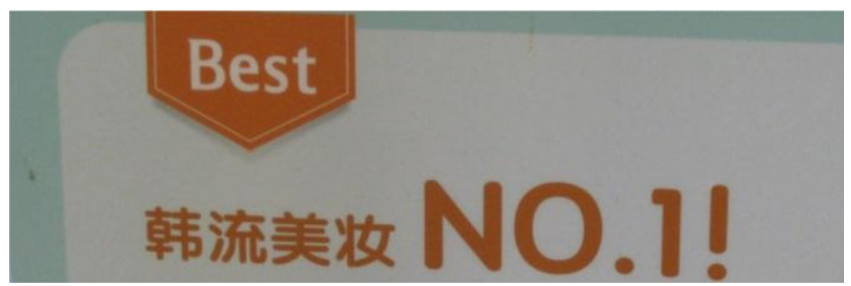

FIGURE 2 Promotional sign of a liquid foundation [Colour figure can be viewed at wileyonlinelibrary.com]

positive trend (sic)' (p. 114). Since the word 'metrosexual' appeared in the media referring to 'an urban male with a strong aesthetic sense who spends a great deal of time and money on his appearance and lifestyle' (Lee, 2006, p. 89), maintaining beautiful skin has also become part of men's grooming routines in South Korea. Kwuripich phipwu ('tanned' or 'bronzed' skin) used to index ultimate masculinity; however, as this sign indicates, stylish men now use a sunblock lotion to protect their skin. In discussing a TV commercial about a liquid foundation marketed exclusively for men, Lee (2006) argues that 'typically female-oriented consumer culture, such as putting on makeup, is no longer identified as exclusively female' in contemporary South Korea (p. 83).

Figure 2 features a sign advertising a popular liquid foundation called BB cream in Insadong. The sign is advertised in two languages: English and Chinese. The sign reads, 'Best 韩流美妆 (hánliú měizhuāng) No. 1!', meaning that it is the best Korean Wave cosmetic. Hanja, which refers to Chinese characters borrowed and incorporated into the Korean language with Korean pronunciation, is used in Korea as well, but we can tell that this particular sign is targeted at Chinese customers because the letters are written in simplified Chinese characters, which are not used in Korea. For example, instead of 韩流美妆 in Figure 2, traditional Chinese characters 韓流化粧 are used in Korea. According to a Reuters article in 2016, 'South Korea last year overtook the United States and Japan to become the No. 2 cosmetics exporter to China after France. It shipped $\$ 1.1$ billion worth of skincare creams, facial masks, compacts and other cosmetic products to the world's second-largest economy, according to the Ministry of Food and Drug Safety'. The linguistic landscape of beauty products illustrates the popularity of K-Beauty products among Chinese tourists, and this particular sign clearly indicates who the intended target audience/potential buyer is.

Using multiple languages is also found in hair salon signs. Figure 3 is from a salon specializing in hair extensions in Myeongdong. It features four languages-Korean, Japanese, English, and Chinese, in that particular order. The sign reads, '붙임 머리 전 문 점 (Pwuthimmeri cenmwuncem 'Hair extension specialty shop') ヘアエクステンション 30 分 完成 (hea ekusutenshon sanjutbung kansei 'Hair extension completed in 30 minutes') Hair extensions completed 30 minutes 头節接头发要 30 分钟 (tóu jié jiē tóu fa yào sānshí fēnzhōng)'. Among the four languages, the Korean part uses the largest font in red and only identifies a type of business (that is, hair extension specialty shop) without any additional explanation; the remaining three languages contain information about how speedily the service can be finished (that is, 30 minutes), which is an appealing sales pitch for tourists with a tight itinerary. Along with hair extensions, nail art seems popular as well. Figure 4 features a handwritten sign containing an English lexical item represented with Koreanized phonological features. A nail art specialty shop named 美甲, which is apparently located inside the beauty parlor named SEMA HAIR on the second floor (2F), is written in Sino-Korean (meaning 'beauty first') and it specifies its main services by listing (1) NAIL Aat ('Nail art' with non-rhotic pronunciation, which is a typical feature of Koreanized English); (2) 젤 글리터 ('Gel glitter' written in Korean script without r-coloring and the flap in the word 'glitter', sounding like 'gulithe'); and (3) 기 본케어 + 칼라 ('kipon care + color' written in Korean and English mixing with non-rhotic pronunciation causing the word color to be pronounced 'kalla').

Tan and Tan (2015) note that most bilingual signs surveyed in their study use English in Korean sentences and they 'are common in areas such as Myeongdong and Ewha streets, where the use of English is widespread' (p. 76). Figure 5 features an exclusively English sign advertising a cosmetics company. It contains an image of a beautiful island called Jeju, which is known for amazing beaches and mountains. A famous actor/singer appearing in this sign is also well 


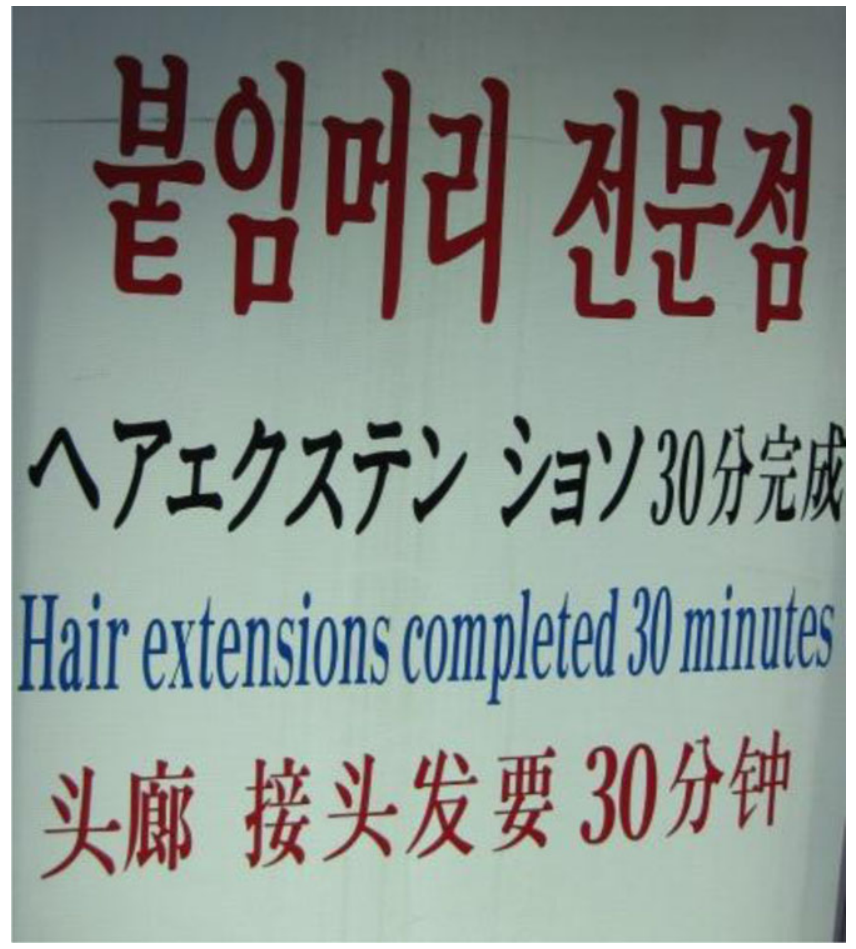

FIG URE 3 Multilingual sign about hair extensions [Colour figure can be viewed at wileyonlinelibrary.com]

known in China, which is why he is often dubbed Hallyu star ('The Korean Wave star'). The copy 'Natural benefit from JEJU' emphasizes organic ingredients used in this company's beauty products. Furthermore, the actor's white outfit and the green pasture in the background remind passersby and potential buyers of Jeju's clean and unpolluted nature, which in turn enhances the image of the company's commitment to using natural ingredients, such as herbs, flowers, and plants, in their products. In fact, the company is self-dubbed as 'Korea No. 1 natural brand' on its website and 'a naturalism-oriented cosmetics brand' (Wikipedia). According to a 2015 Research and Markets report, 'the South Korean market for natural \& organic cosmetics is one of the fastest growing in Asia'. Revenues are increasing at double digits because of high consumer demand for natural and organic products. Johri and Sahasakmontri (1998) observe that the 'use of traditional cosmetics and toiletries manufactured from herbs and plant extracts has been popular in many Asian countries. However, green marketing of these products is rather recent' (p. 265). Almost 20 years after Johri and Sahasakmontri's article was published, 'green marketing' is now widely promoted, which is exemplified in Figure 5, as more consumers are environmentally-conscious.

\section{2 | Food and drink}

Chan and Huang (2001) note that place names tend to be used extensively in branding traditional products. The linguistic landscape of food in this study shows similar tendencies. An illustrative example of this was found in a handwritten sign by a street vendor selling uniquely Korean hard taffy called 'yeot' in Insadong (Figure 6). The sign reads, 대 패 생 강엿 울릉도 호박엿 (tayphay sanggak yeot Wulungdo hopakyeot, 'thinly sliced ginger hard taffy Wulungdo pumpkin hard taffy'). The sign makes specific reference to an island called Wulungdo, which is famous for its pumpkin and ginger hard candy. Lee (2006) treats taste as a cultural form and contrasts Korean only (KO) commercials and English mixing (EM) commercials, arguing that 'EM represents modern taste, whereas KO represents traditional taste' (p. 83). It is further noted that 'certain categories of products are advertised in Korean-only commercials' and 'Korean food (e.g., rice, 


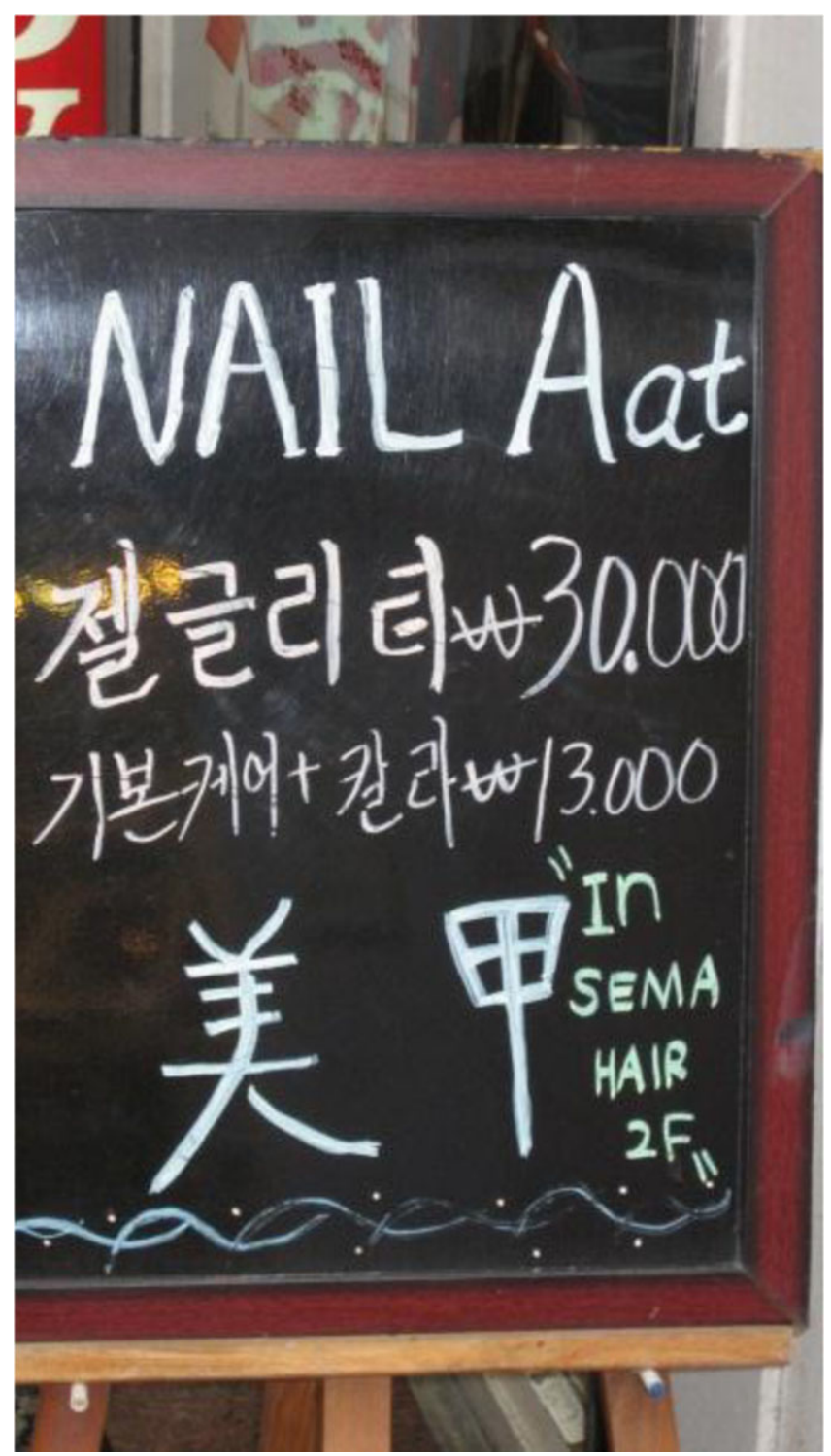

FIGURE 4 Sign advertising various nail art services [Colour figure can be viewed at wileyonlinelibrary.com]

Korean plum drink, Korean noodles, Korean meat) or home appliances for preparing Korean food (e.g., a specialized refrigerator for kimchi)' are advertised in Korean (p. 74). Lee (2006) argues that 'the noticeable absence of English in Korean commercials signifies tradition and not the construction of modernity' (p. 87). In Figure 6, no English is used. Moreover, the letters are written in a somewhat old-fashioned font called 'kwungsechey'. We can infer, based on the street vendor's linguistic choices, that he or she views their main customers as Koreans, especially older Koreans who would appreciate this traditional hard candy they used to taste when they were children. Stern (1990) discusses 'nostalgic typologies' linking the brand to 'a favorably recollected past' and 'childhood satisfaction' (p. 22).

On the other hand, when a food item is available in other cultures, it is advertised in multiple languages to attract foreign tourists who would appreciate that type of linguistic accommodation. Figure 7 features a café sign advertising a shaved ice dessert with red beans and fruits. The café owner clearly has Japanese and Chinese customers in mind since its Japanese equivalent かき氷 (kakigoori) and Chinese equivalent 紅豆冰 (hóngdòubīng) are provided next to 


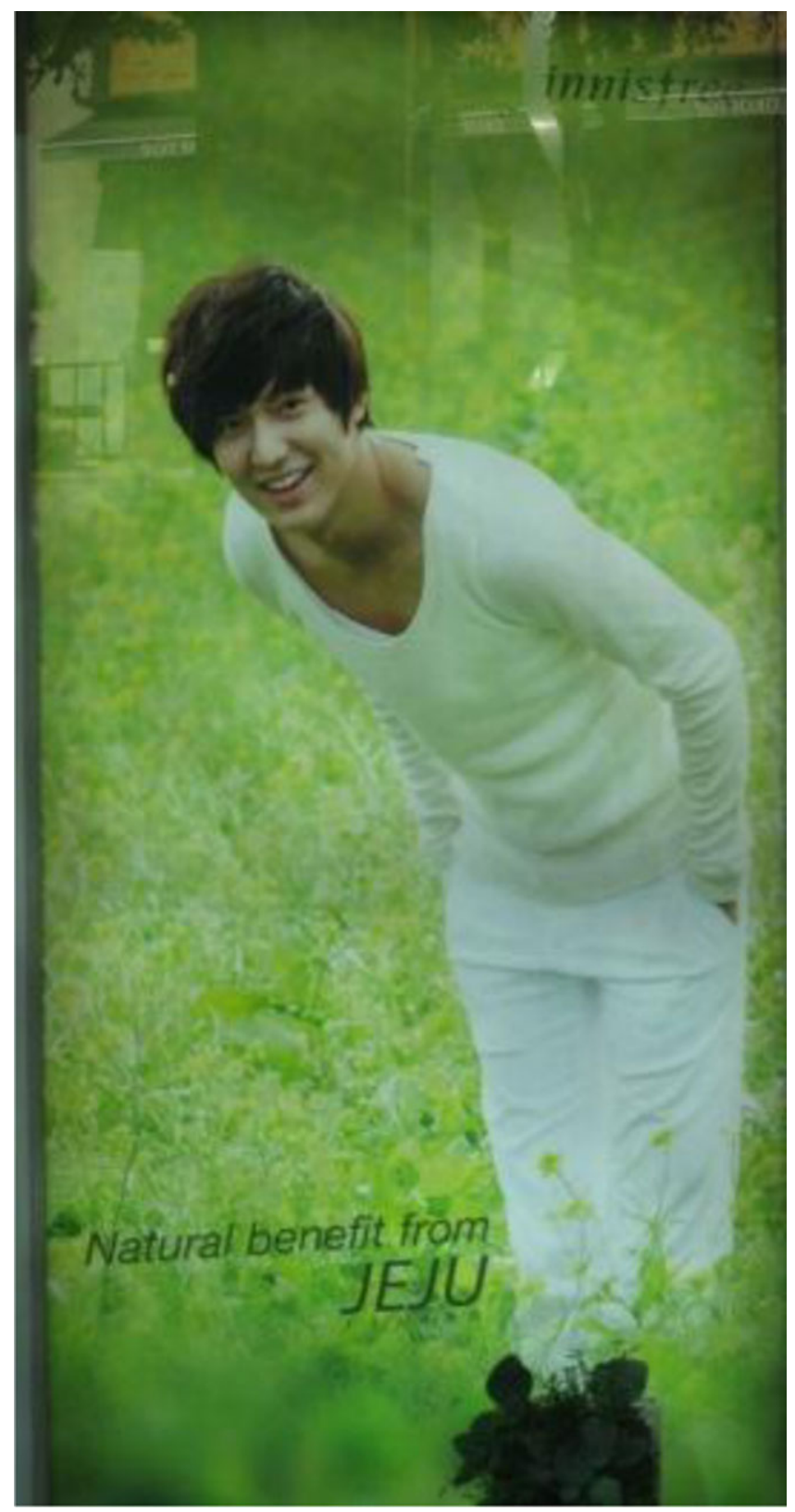

FIGURE 5 Cosmetics manufacture's green marketing sign [Colour figure can be viewed at wileyonlinelibrary.com]

the Korean equivalent. It can be inferred from the linguistic choices on the sign that this ice dessert is available in East Asian countries although their names differ from one country to another.

One would assume that coffee shop signs would be generally presented in some English. In most cases, it is true especially for well-known franchises managed by large companies. Lee (2006) reports that TV commercials about coffee or coffee-flavored drinks tend to use English mixing. However, in an area such as Insadong, which values traditions and 'Korean stuff', some coffee shop signs are written in Korean. Lawrence (2012) reports that 'Insadong is famous for forcing Starbucks to write its sign in Korean. People in the area proudly told [him] that it is the only case in the world where Starbucks did not use the English alphabet' (p. 80). He further notes that 'it was government policy to have all 


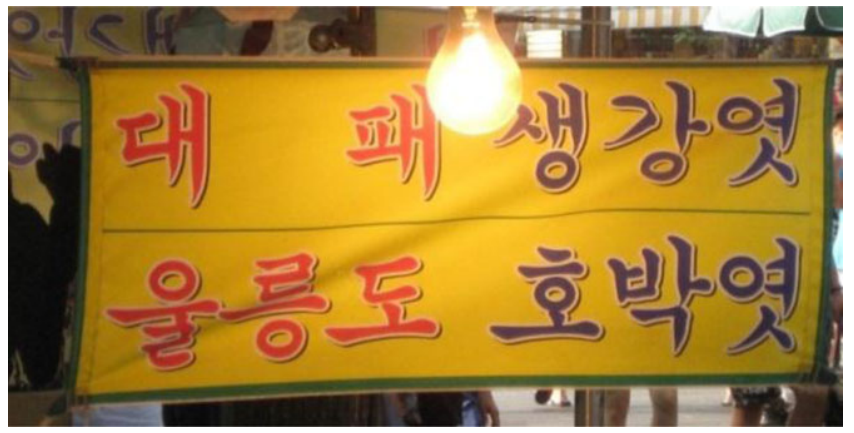

FI GURE 6 Street vendor's sign about traditional Korean taffy [Colour figure can be viewed at wileyonlinelibrary.com]

outdoor signs in Korean' (Lee, 2001 cited in Lawrence, 2012. P. 80). Although this policy is not always strictly followed, many signs in Insadong are indeed written exclusively in Korean, including some coffee shops. Figure 8 is a case in point; it is a coffee shop sign that contains no English. Even the word 'coffee' is presented in Korean script 커 피. Also, notice the sign is made out of traditional rice paper, and the script is presented in a calligraphy style as well. The sign reads, 'Emperor's coffee aged in a clay pot'. The use of the word hangari ('clay pot') is also noticeable, as it is normally used to store traditional Korean fermented seasonings, sauces, and side dishes; it stands for something traditional and unchanging in quality over the years.

There are different terms to refer to coffee shops in Korea. Café is generally reserved for trendy coffee shops catering to young Korean students and professionals. The word 'coffee shop' normally refers to a coffee house at a luxurious hotel. Chatcip (literally 'tea house') in Figure 9 is generally used by older generations referring to a place where you can drink tea. Particularly, this sign found in Insadong uses a prefix 옛 (yeyt) literally meaning 'old'. The background is white, and the letters are written in black in an unmistakable calligraphy style, bearing a resemblance to white rice paper and the black ink stone. Not surprisingly, English is nowhere to be found in this sign. After all, the word 'old' is the opposite of new and modern. Many studies on advertising suggest that English is often associated with modernity. Friedrich (2002) argues that English 'symbolizes modernity', has 'a connotation of Westernization', and functions as 'extra linguistic material, to quench the creative thirst of advertisers and businesspeople all over the world' (p. 22). Takashi (1990) also notes that the use of English borrowings in Japanese TV commercials and print ads appeals to 'modern' and 'cosmopolitan' young consumers (p. 327). 옛찻집 in Figure 9 is not intimately connected to the notion of modernity; therefore, it is natural that we do not see English in this sign. Tapang (茶房), which used to be a regular fixture in the coffee and tea drinking industry but has now practically disappeared in contemporary Korea, literally means 'tea room'. It was a popular term used before the word café became widely available. It is rare to see the word 'tapang' these days, let alone use it in conversation in Korea. If it is used, we can generally tell that the individual is from an older generation. However, in Figure 10 featuring a coffee shop called 별 다방 미스리 (Pyel tapang Miss Lee, 'Star Tea Room Miss Lee'), we see that it has made its comeback indicating a retro style and nostalgic marketing. To add some interesting background information about coffee shops, Starbucks is jocularly dubbed 'pyel tapang' in Korea because the word 'star' is 'pyel' in Korean. When celebrities are not allowed to mention any product names on TV, they tend to use another word or English initials because their explicit endorsement is prohibited and they do not want to appear to be promoting particular products. So they often say 'pyel tapang' in place of Starbucks on TV. It is noteworthy that the coffee shop featured in Figure 10 goes against the trend of giving English names to Western-style coffee shops; instead, it uses an old fashioned nostalgic name tapang with the English part 'Miss Lee' written in Korean script.

Similarly, in their discussion of the predominant presence of English in the Pakistani linguistic landscape, Manan et al. (2017) comment on the trend of English being represented 'in the localized non-Roman script', for example, Urdu or Arabic/Persian script (p. 645). The term 'Miss Lee' (pronounced 'Missuri') is a remnant of an old Korea in 


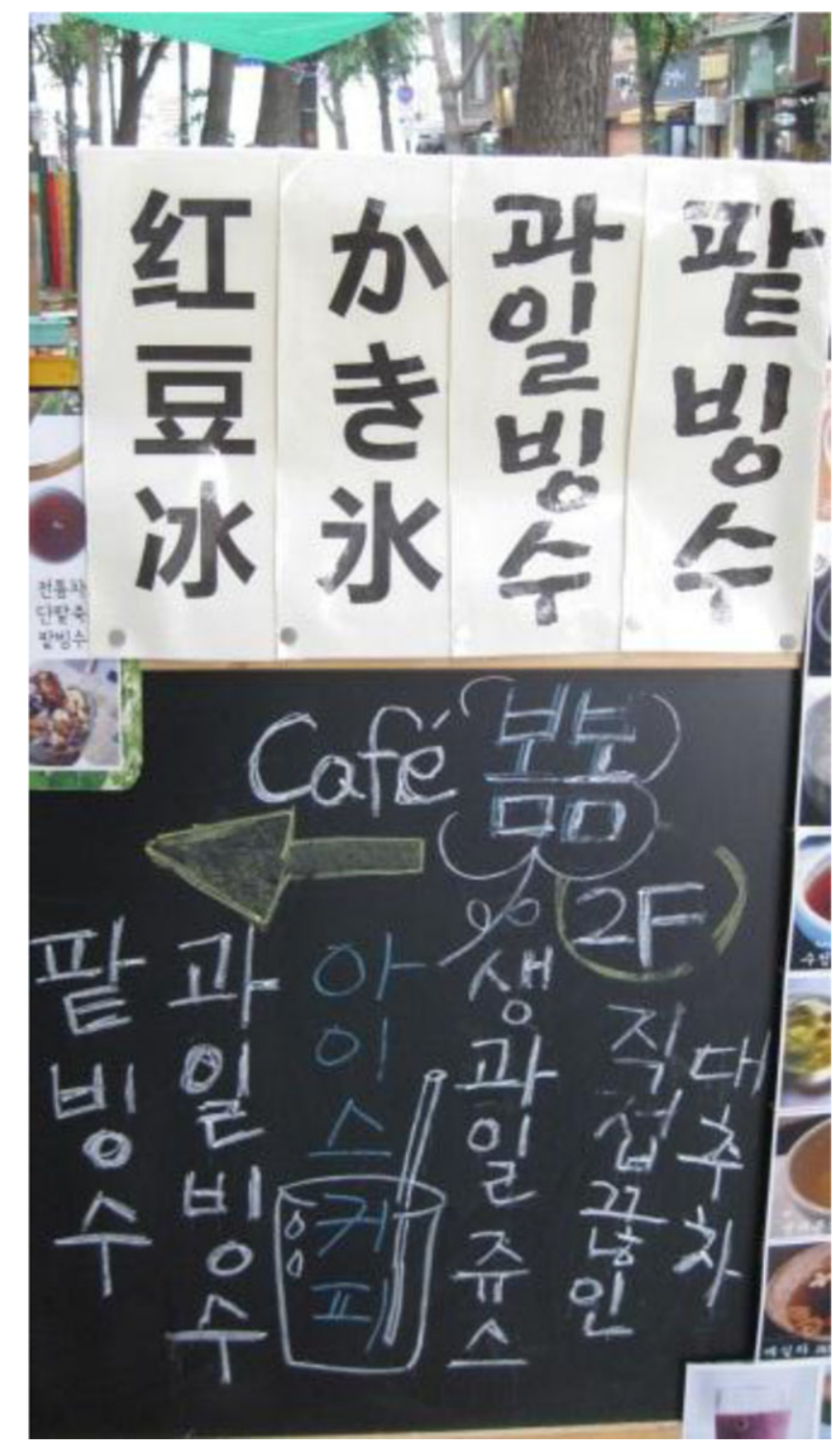

FIGURE 7 Multilingual café sign promoting an ice dessert [Colour figure can be viewed at wileyonlinelibrary.com]

which an unmarried female office worker was addressed by the title 'Miss' followed by their last name. Korean coffee shops in the 1960s and 1970s used to have what they called 'Madam', referring to the female owner of the coffee shop, and 'leji' (which is a Japanized pronunciation of the English word 'lady'). Lejies (Miss Lee, Miss Kim, Miss Park, and so forth) essentially played triple roles: waitresses serving coffee, hostesses sitting and chatting with customers, and deliverers carrying coffee to businesses and offices, which is not available anymore. In this coffee shop sign, we see a retro language feature from the past. The exclusive use of the Korean language appears in the linguistic landscape of food too, particularly in business signs specializing in food that mainly appeals to Koreans because of its unmistakably pungent smell, such as 청 국 장 (chengkwukcang, 'fermented bean paste stew'), as shown in Figure 11. However, if a particular Korean dish is popular among foreign tourists, its name is also presented in a language that is understandable to that specific target group along with Korean. For instance, in Figure 12, a Korean restaurant in Insadong called 민 속촌식당 土房 (Misokchonsiktang thopang, 'Folk Village Restaurant Thopang') lists its signature 


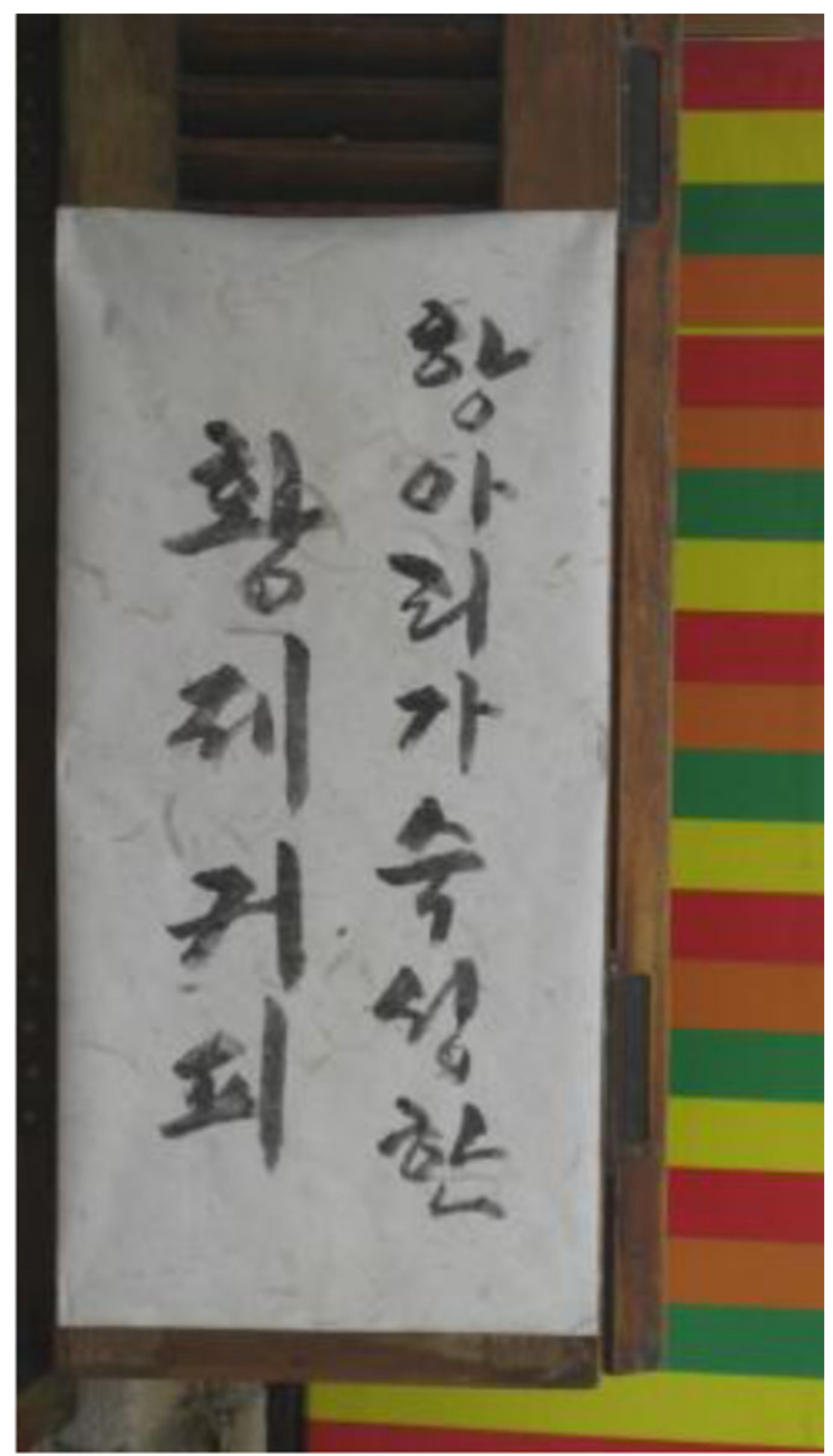

FIGURE 8 Korean sign about coffee [Colour figure can be viewed at wileyonlinelibrary.com]

dishes, including 김치찌개 (kimchi ccikay, 'kimchi stew'), 된장찌개 (toyncang ccikay, 'soy bean paste stew'), 순부두찌 개 (swuntwupwu ccikay, 'soft tofu stew'), and 비빔 밥 (pipimpap, 'rice with assorted mixtures of vegetables), as well as traditional drinks, such as 동 동주 (tongtongcwu, 'rice wine') and 막걸리 (makkeli, 'unrefined rice wine'). The name of the restaurant is written in Sino-Korean (Chinese characters readily used in Korean) accentuating its traditional feel, and each of the signature dishes written in Korean has a Japanese equivalent. It is worth pointing out that Japanese equivalents are phonologically close to Korean counterparts, not direct translations, and they are written in a much smaller font.

Another noteworthy feature in the linguistic landscape of food is the specification of an original place that is known for the dish. Place names associated with particular food because of its long tradition, authenticity, and originality are often incorporated into restaurant names. 'The authenticity of touristic gastronomic experience' and 'The tendency 


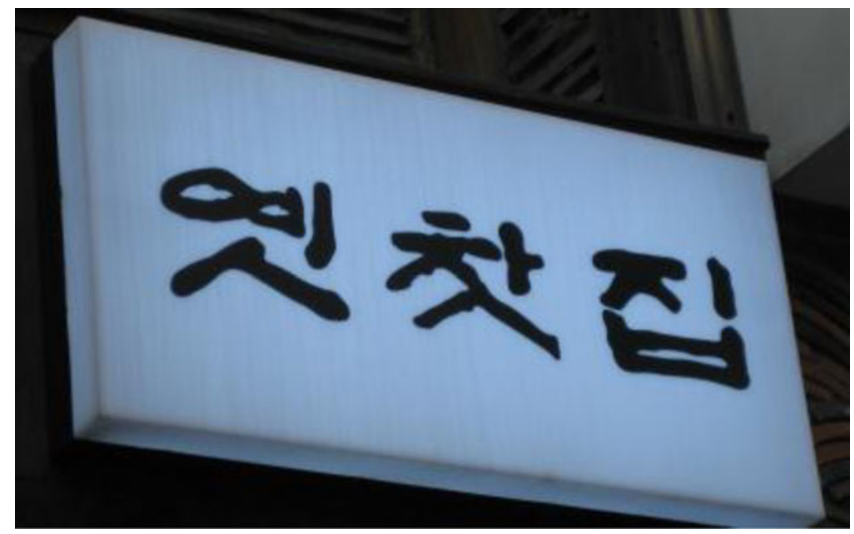

FIGURE 9 Traditional tea house sign [Colour figure can be viewed at wileyonlinelibrary.com]

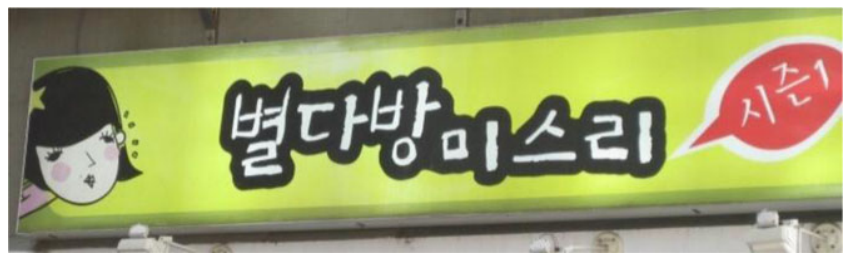

FIGURE 10 Coffee shop sign using retro marketing [Colour figure can be viewed at wileyonlinelibrary.com]

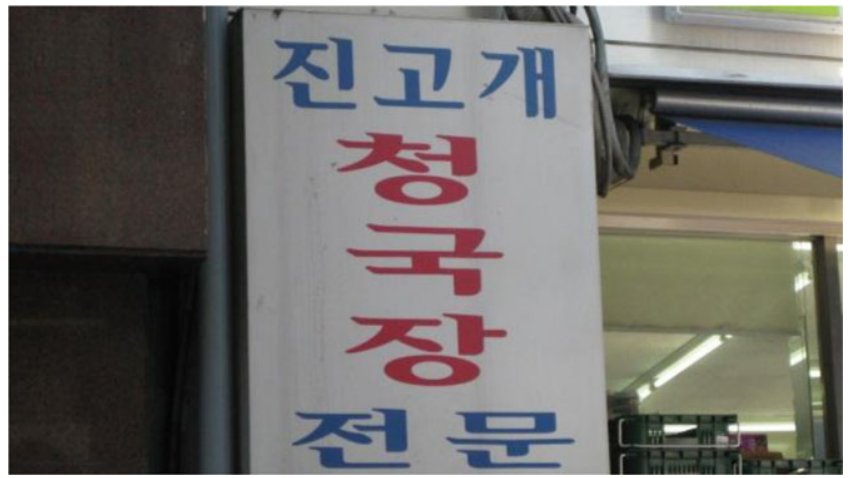

FIG URE 11 Restaurant sign specializing in Korean fermented soy bean paste soup [Colour figure can be viewed at wileyonlinelibrary.com]

toward authenticity' are often emphasized as a sales pitch in tourism (Cohen \& Avieli, 2004; Gordin, Trabskaya, \& Zelenskaya, 2016; Lin, Pearson, \& Cai, 2011). Myeongdong's handmade chopped noodles called 명 동 칼 국수 (Myeongdong khalkwuksu) is a case in point. The noodle restaurant in Figure 13 is located in Insadong, but the name of the restaurant contains another area in Seoul, that is, Myeongdong, which is famous for these kind of noodles. The sign reads, '明洞 刀切面 (míngdòng dāoqiēmiàn) 명 동 칼국수 明洞カルクッス' featuring four different languages: Chinese, Korean, Japanese, and English. The Korean part is placed in the center, written in the largest font. Chinese with the same meaning appears above Korean, and the Japanese part is placed below Korean. It is noteworthy that the Japanese version uses the expression approximating the Korean pronunciation, カルクッス (karukutsu) instead of きしめん (kishimen), which is the Japanese counterpart. There are two additional expressions written in Korean: 인 사 동 


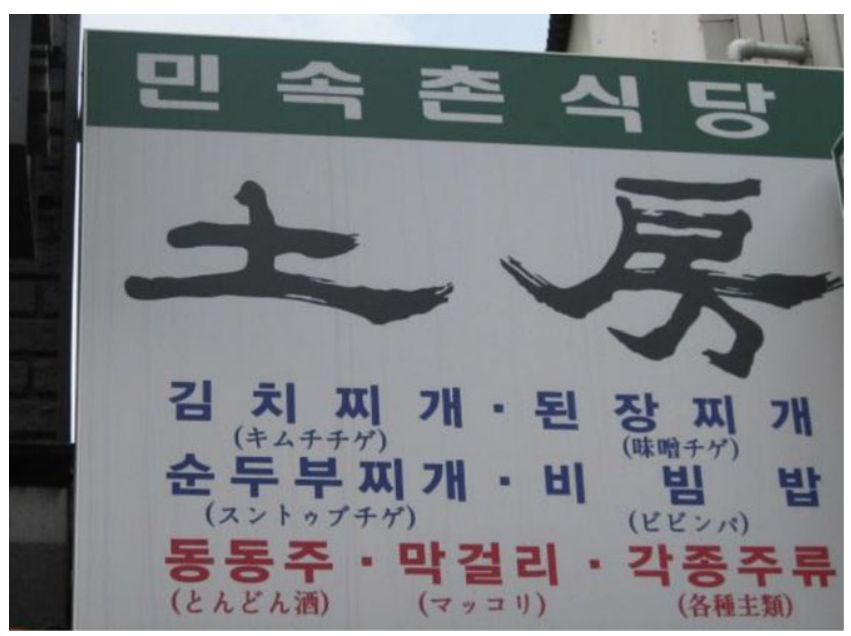

FIGURE 12 Korean restaurant sign featuring Sino Korean, Korean, and Japanese [Colour figure can be viewed at wileyonlinelibrary.com]

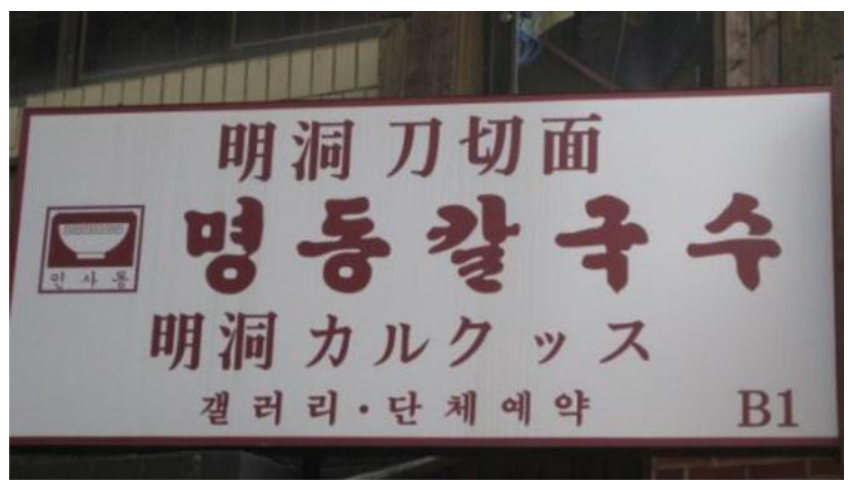

FI GURE 13 Restaurant sign specializing in handmade chopped noodles [Colour figure can be viewed at wileyonlinelibrary.com]

(Insadong), placed under the image of the noodle bowl, and 갤러리. 단체 예 약 (kayleri. tanchey yeyyak, 'gallery group reservation'), meaning that they accept group reservations, including galleries, which are common in Insadong. The only English expression is 'B1' in the right bottom corner, indicating that the restaurant is located in the building's basement.

Multilingualism is also present in restaurant signs in Myeongdong. In a breakfast place called 'Waffle Bant' (Figure 14), its advertisement is represented in two languages: Japanese (kanji and katakana) and English. English, that is, 'Traditional Belgian Waffle', appears first followed by its exact translation in Japanese, 正統 (seito, 'traditional') ベル ギー産 (bergi-san, 'made in Belgium' or 'originated from Belgium') ワッフル (wafuru, 'waffle')'. Similarly, other dishes are also specified in English first (as in, 'Premium coffee \& Ice Cream') followed by the exact same meaning in Japanese. Korean is conspicuously missing although Sino-Japanese called kanji (that is, 正統 and 産) are still intelligible to Korean customers. Considering that it is a Western-style café, the use of English is not surprising. However, the use of Japanese indicates that the restaurant aims to appeal to Japanese customers too.

When no other languages are present except Korean, it generally features traditional Korean food or home-style cooking. A restaurant specializing in grilled fish has a business sign exclusively written in Korean except the location (2F). The name of the restaurant is 어 머 니 생 선 (emeni sangsun, 'Mother's Fish') (Figure 15), which is a condensed version of the phrase 어머니가 구워주신 생선 구이 (emeni-ga kwuwecwusin sangsen kwui, 'Grilled fish my mother 


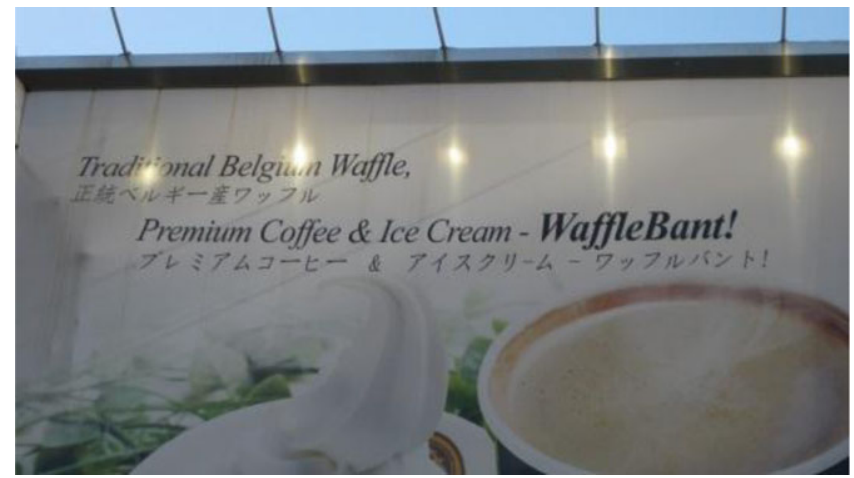

FIG URE 14 Breakfast café sign promoting its signature menu [Colour figure can be viewed at wileyonlinelibrary.com]

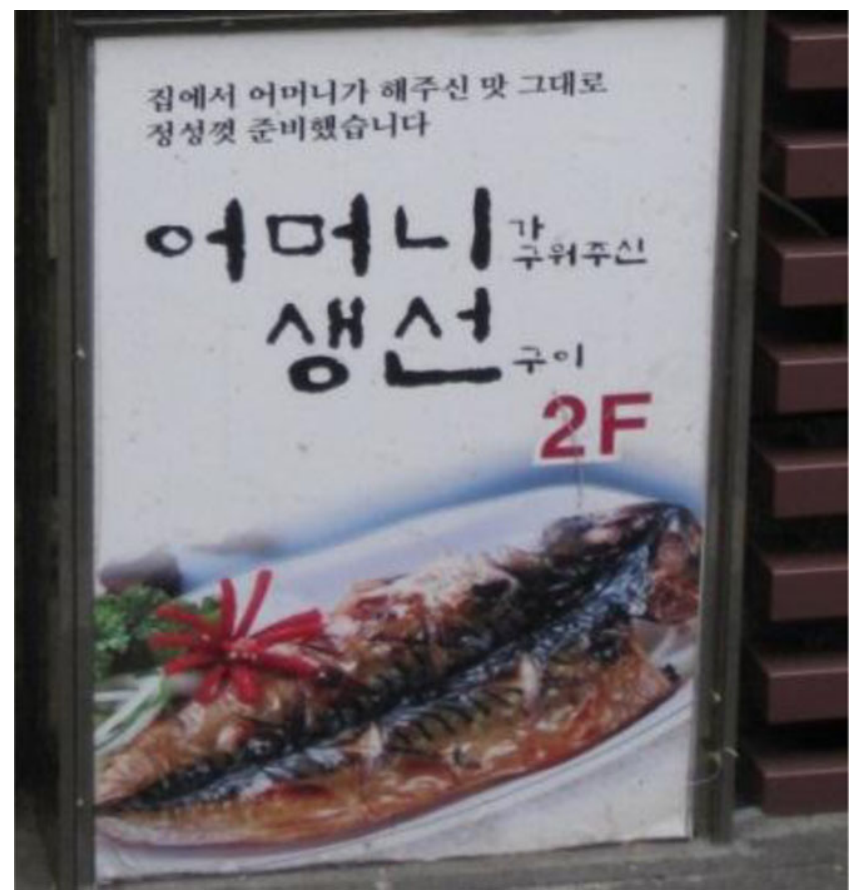

FIG URE 15 Grilled fish restaurant sign advertising home-style cooking [Colour figure can be viewed at wileyonlinelibrary.com]

cooked for me'). It is written in smaller print and only two keywords are selected and highlighted in the restaurant name, 어 머 니 (emeni, 'mother') and 생 선 (sangsen, 'fish'). The name of the restaurant is placed in the center, and an additional description, or 'sales pitch', appears right above in smaller print, meaning 'we cook our fish with great care and dedication just like your mom would at home' (집 에서 어 머니가 해주신 맛 그대로 정 성껏 준비 했습니다).

A kajungsik (home-style cooking) restaurant advertising 'mom's touch' relies solely on the local language, lacking the influence of the global language, English. Evoking mother's love is accomplished through mother's language, Korean. Although it is not part of the data for this study, it is necessary at this juncture to mention a well-known franchise called Mom's Touch in Korea, which uses only English. What is the difference between the two? After all, both restaurants use the concept of mom's cooking. Mom's Touch is a chicken burger chain and has a Westernized menu serving 


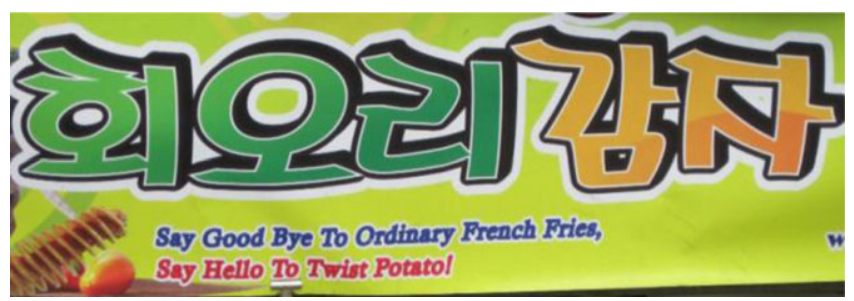

FIGURE 16 Street vendor sign advertising upgraded French fries [Colour figure can be viewed at wileyonlinelibrary.com]

mainly chicken wings, chicken burgers, and hamburgers. It is managed and controlled by a company that, according to Wikipedia, has over 650 retail stores in South Korea as of 2015. It is not a 'mom-and-pop store' in your neighborhood, like Mother's Fish, that is owned by an individual and run by family members. Even the physical space of Mom's Touch looks very different from that of 어머니 생선. Mom's Touch has a Westernized interior with bright colors. Both Mom's Touch and 어머니 생선 essentially have the same sales pitch and cooking philosophy, that food is prepared and served in the same way your mother would for your family, namely ' with love'. This is linguistically represented in a contrastive way to reflect their respective signature menus, that is, Korean style home cooking and Western fast food.

So far, we have mainly discussed professionally produced business signs, but this study also examines street vendors' signs, which interestingly reveal similar linguistic choices. In contrast to an exclusively-Korean sign advertising traditional Korean hard candy (such as in Figure 6), Figure 16 shows a street vendor sign selling an upgraded version of French fries with a noteworthy catchphrase in English: 'Say Good Bye to Ordinary French Fries, Say Hello to Twist Potatoes'. This improved potato snack is called 회오리 감자 (hoyori kamca) literally meaning 'tornado potato' because of its twisted appearance. Since French fries are not a traditional Korean snack, using English to advertise newly developed potato twists can be argued as a sensible linguistic choice. It is also noticeable that well-known English idiomatic expressions are introduced as parallel structures, in 'Say Good Bye' and 'Say Hello'.

\section{6 | CONCLUSION}

Business signs in the two popular tourism districts discussed in this study feature multiple languages: Korean, English, Chinese, and Japanese. Findings of the present study seem to suggest that language choices in the linguistic landscape are dictated in one way or another by products sold, neighborhood specialties, targeted consumers (especially their languages), and perceived economic affordability. Based on linguistic choices, it is possible to infer, for instance, which products are particularly popular among Chinese visitors and Japanese visitors. By analyzing featured languages and their content and roles in signage, the study argues that the beauty industry relies heavily on English in general, but the power of K-Beauty popularized by 'Hallyu' (The Korean Wave) beyond Korea inevitably invites linguistic accommodation resulting in the use of Chinese and Japanese on posters and in marketing materials. I argue that the same product can be advertised differently, and the same business type can show dissimilar linguistic decisions depending on chosen images and marketing strategies. For example, coffee shops run by a mega franchise tend to write their signs mostly in English, while several cafes in Insadong, known for traditional artefacts, use Korean script to represent English.

Furthermore, not all 'Korean stuff' is always represented exclusively in Korean. The study argues that targeted consumers or diners likely influence business owners' linguistic choices in shop signs and promotional posters. For instance, a dish that is 'too Korean'-meaning a dish that only Koreans can handle because of its smell (for example, chengkwukcang, 'fermented soybean paste soup'), spiciness (for example, maywun ccamppong, 'extra spicy noodles'), texture (such as sannakci, 'live baby octopus'), or shape (such as takpal, 'chick feet')-is highly likely to be advertised in 
Korean only. On the other hand, if it is already well-known to non-Koreans and enjoyed by many foreigners, other languages will be summoned to advertise a classic Korean dish. Therefore, depending on the additional language used in a particular sign, one can confidently infer who the main consumer group is. As popular tourist attractions, Myeongdong and Insadong share many features. However, they also demonstrate different business orientations. Nonetheless, the business category of beauty features a much more prevalent use of English than that of food. Moreover, Insadong, as an area specializing in traditional goods, shows more signs exclusively in Korean than in Myeongdong. In future research endeavors, it will be worth investigating other tourism districts located outside the capital, preferably in noncosmopolitan cities, to see if multilingual signs are as common and linguistic accommodations as readily available as in this study.

\section{NOTES}

${ }^{1}$ http://packagekorea.com/wp-content/uploads/2013/09/insadong_map_02.jpg

${ }^{2}$ http://english.visitkorea.or.kr/enu/ATR/SI_EN_3_1_1_1.jsp?cid=264354

${ }^{3}$ http://ontheworldmap.com/south-korea/city/seoul/myeong-dong-euljiro-map-max.jpg

${ }^{4}$ http://english.visitseoul.net/shopping/Myeong-dong_/68

${ }^{5}$ http://english.visitkorea.or.kr/enu/ATR/SI_EN_3_1_1_1.jsp?cid=264312

\section{REFERENCES}

Bano, S., \& Sharif, M. A. M. (2016). Metrosexual: Emerging and lucrative segment for marketers. International Review of Management and Marketing, 6(4), 114-119.

Bhatia, T. K. (1992). Discourse functions and pragmatics of mixing: Advertising across cultures. World Englishes, 2(1), $195-215$. Bhatia, T. K. (2008). World Englishes in global advertising. In B. B. Kachru, Y. Kachru, \& C. L. Nelson (Eds.), The Handbook of world Englishes (pp. 601-619). Malden, MA: Blackwell.

Bolton, K. (2012). World Englishes and linguistic landscapes. World Englishes, 31(1), 30-33.

Bourdieu, P. (1991). Language and symbolic power. Cambridge, Massachusetts: Harvard University Press.

Cenoz, J., \& Gorter, D. (2006). Linguistic landscape and minority languages. International Journal of Multilingualism, 3(1), 67-80.

Chan, A. K. K., \& Huang, Y. (2001). Chinese brand naming: A linguistic analysis of the brands of ten product categories. The Journal of Product and Brand Management, 10(2), 103-119.

Chua, B. H., \& Iwabuchi, K. (2008). Introduction: East Asian dramas. In B. H. Chua \& K. Iwabuchi (Eds.), East Asian pop culture: Analysing the Korean Wave (pp. 1-12). Hong Kong: Hong Kong University Press.

Cohen, E., \& Avieli, N. (2004). Food in tourism: Attraction and impediment. Journal of Tourism Research, 31(4), $755-778$.

Dimova, S. (2007). English shop signs in Macedonia. English Today, 23(3/4), 18-24.

Friedrich, P. (2002). English in advertising and brand naming: Sociolinguistic considerations and the case of Brazil. English Today, 18(3), 21-28.

Gordin, V., Trabskaya, J., \& Zelenskaya, E. (2016). The role of hotel restaurants in gastronomic place branding. International Journal of Culture, Tourism and Hospitality Research, 10(1), 81-90.

Inagawa, M. (2015). Creative and innovative uses of English in contemporary Japan. English Today, 31(3), 11-16.

Johri, L. M., \& Sahasakmontri, K. (1998). Green marketing of cosmetics and toiletries in Thailand. The Journal of Consumer Marketing, 15(3), 265-281.

Kasanga, L. (2012). English in the Democratic Republic of the Congo. World Englishes, 31(1), 48-69.

Lanza, E., \& Woldemariam, H. (2014). Indexing modernity: English and branding in the linguistic landscape of Addis Ababa. International Journal of Bilingualism, 18(5), 491-506.

Lawrence, C. B. (2012). The Korean English linguistic landscape. World Englishes, 31(1), 70-92.

Lee, J. S. (2006). Linguistic constructions of modernity: Korean-English mixing in TV commercials. Language in Society, 35(1), 59-91.

Lee, J. S. (2010). Commodified English in East Asian internet advertising. In H. Kelly-Holmes \& G. Mautner (Eds.), Language and the market (pp. 109-120). New York: Palgrave-Macmillan.

Lee, J. (Joyce). (August 3, 2016). Fast beauty: Korean cosmetics shine in China, draw investors. Reuters. Retrieved from https://www.reuters.com/article/southkorea-cosmetics-idUSL4N1A82DF

Lee, S. (2018). Hit by high rent, Insa-dong loses its identity. The Korea Times. Retrieved from http://koreatimes.co.kr/www/ news/culture/2018/03/135_246189.html 
Leeman, J., \& Modan, G. (2009). Commodified language in Chinatown: A contextualized approach to linguistic landscape. Journal of Sociolinguistics, 13(3), 332-362.

Lin, Y-C., Pearson, T. E., \& Cai, L. A. (2011). Food as a form of destination identity: A tourism destination brand perspective. Tourism and Hospitality Research, 11(1), 30-48.

Manan, S. A., David, M. K., Dumanig, F. P., \& Khan, N. (2015). Politics, economics and identity: Mapping the linguistic landscape of Kuala Lumpur, Malaysia. International Journal of Multilingualism, 12(1), 31-50.

Manan, S. A., David, M. K., Dumanig, F. P., \& Channa, L. A. (2017). The glocalization of English in the Pakistan linguistic landscape. World Englishes, 36(4), 645-665.

Martin, E. (2007). 'Frenglish' for sale: Multilingual discourses for addressing today's global consumer. World Englishes, 26(2), 170-190.

Ong, K. K., Wee, G., François, J., \& Serwe, S. K. (2013). Frenglish shop signs in Singapore. English Today, 29(3), 19-25.

Ross, N. J. (1997). Signs of International English. English Today, 13(2), 29-33.

Scollon, R., \& Scollon, S. W. (2003). Discourses in place: Language in the material world. London: Routledge.

Selvi, A. F. (2016). English as the language of marketspeak: Reflections from the linguistic landscape of Turkey. English Today, 32(4), 33-39.

Shang, G., \& Guo, L. (2017). Linguistic landscape in Singapore: What shop names reveal about Singapore's multilingualism. International Journal of Multilingualism, 14(2), 183-201.

Spolsky, B., \& Cooper, R. L. (1991). The languages of Jerusalem. Oxford: Clarendon Press.

Stern, B. B. (1990). Other-speak: Classical allegory and contemporary advertising. Journal of Advertising, 19(3), 14-26.

Takashi, K. (1990). A sociolinguistic analysis of English borrowings in Japanese advertising texts. World Englishes, 9(3), $327-341$.

Tan, S. X., \& Tan, Y. (2015). Examining the functions and identities associated with English and Korean in South Korea: A linguistic landscape study. Asian Englishes, 17(1), 59-79.

Vandenbroucke, M. (2016). Socio-economic stratification of English in globalized landscapes: A market-oriented perspective. Journal of Sociolinguistics, 20(1), 86-108.

Vestergaard, T., \& Schrøder, K. (1994). The language of advertising. Oxford/New York: Basil Blackwell.

Weyers, J. R. (2015). English shop names in the retail landscape of Medellín, Colombia. English Today, 32(2), 8-14.

How to cite this article: Lee JS. Multilingual advertising in the linguistic landscape of Seoul. World Englishes. 2019;38:500-518. https://doi.org/10.1111/weng.12427 